\title{
Rainfall variability and vegetation dynamics in the Mauritanian Sahel
}

\author{
O. C. A. Ahmedou ${ }^{1,4,}$, R. Nagasawa ${ }^{2}$, A. E. Osman ${ }^{3}$, K. Hattori ${ }^{2}$ \\ ${ }^{1}$ United Graduate School of Agricultural Sciences, Tottori University, Koyama Minami 4-101, Tottori 680-8553, Japan \\ ${ }^{2}$ Faculty of Agriculture, Tottori University, Koyama Minami 4-101, Tottori 680-8553, Japan \\ ${ }^{3}$ Arid Land Research Center, Tottori University, Hamasaka 1390, Tottori 680-0001, Japan \\ ${ }^{4}$ Present address: Institut Supérior d'Enseignement Technologique (ISET-Rosso), BP 40012, Nouakchott, Mauritania
}

\begin{abstract}
To evaluate the state of ecosystems in Mauritania, rainfall time series and a GIMMSNDVI (global inventory modeling and mapping study-normalized difference vegetation index) data set were used for analysis of rainfall and NDVI trends and their relationships in different ecological zones. Linear regression analysis and the non-parametric Mann-Kendall test were applied to detect NDVI and rainfall trends. In addition, the interannual NDVI coefficient of variation (CV) was used to demarcate the borders of the Mauritanian Sahel, and used as an index for land degradation. The results of both parametric and non-parametric methods confirmed the presence of increasing rainfall trends in different ecological zones, except for the Saharan and coastal zones. However, NDVI time series were positive at east Sahel and southeast Senegal River zone. As concluded from trends of rainfall and NDVI, and from CV analysis, the west Mauritanian Sahel and zones west of the Senegal River were characterized by low performance and presence of degradation, while the east Sahel zone, the zone to the southeast of the Senegal River, and patchy areas in the west Sahel exhibited very good land performance and greenness during 1983-2003. The actual borders of Mauritanian Sahel rangeland approximate to the $200 \mathrm{~mm}$ isohyet and 0.20 mean NDVI. Land degradation in the Mauritania Sahel can be attributed principally to human activities, and the recent greenness to the increase in rainfall.
\end{abstract}

KEY WORDS: Ecosystems $\cdot$ NDVI $\cdot$ Tendency $\cdot$ Rainfall records $\cdot$ Mauritania

\section{INTRODUCTION}

Mauritania extends over $>1$ million $\mathrm{km}^{2}$ of northwest Africa. The Sahara desert covers the northern part of the country and the Sahel zone borders this to the south. The vegetation cover in Mauritania is composed mainly of grass and shrub lands in the semi-arid zone (Sahel) and sparse vegetation in the arid zone (Sahara). Identification of the exact limits between Sahara and Sahel is difficult. However, the 100-200 and 400-600 $\mathrm{mm} \mathrm{yr}^{-1}$ rainfall contours are generally accepted as the northern and southern Sahelian limits, respectively (Anyamba \& Tucker 2005).

The West African Sahel has experienced the most substantial and sustained decline in rainfall recorded in the world since rain-gauge measurements began in the late 1800s (Nicholson 2000). As part of the West
African Sahel, Mauritania has been experiencing frequent droughts since the late 1960s, which have been more severe than in the neighboring countries due to its position at the immediate southern fringe of the Sahara desert (Thiam 2003). Demarré (1990) found a highly significant downward trend in the Sahelian rainfall (using rain gauge records from Kaedi station, southern Mauritania) between 1904 and 1988. Furthermore, Ahmedou et al. (2008) found a significant rainfall decrease during 1931-1980 in north Mauritania, which resulted in persistent drought in this region. However, recent findings suggest a consistent trend of increasing vegetation in much of the Sahel region (Olsson et al. 2005) and an increase in the rainfall amounts (excluding the northernmost zone, i.e. the Sahara margin) compared to the periods of droughts (Nicholson 2005). 
The satellite images series of the National Oceanic and Atmospheric Administration (NOAA) Advanced Very High Resolution Radiometer (AVHRR) sensor provides a dataset that is useful for the analysis of spatiotemporal changes of vegetation cover and land degradation. The foundation for using Normalized Difference Vegetation Index (NDVI) data, including AVHRR-NDVI, in monitoring arid and semi-arid lands is based on a large body of research in the late 1980s demonstrating the close relationship between NDVI and rainfall variations at seasonal to interannual time scales (Anyamba \& Tucker 2005). In general, NDVI is a sensitive indicator of the interannual and spatial variability of rainfall in semiarid zones (Li et al. 2004). The changes in precipitation were identified by Hickler et al. (2005) as the main cause of vegetation changes.

Because of its geographical location, Mauritania is particularly vulnerable to climatic changes. Several studies have examined the dynamics of vegetation in all countries of the Sahel (i.e. Fuller 1998, Milich \& Weiss 2000, Diouf \& Lambin 2001, Thiam 2003, Tappan et al. 2004, Anyamba \& Tucker 2005, Herrmann et al. 2005, Olsson et al. 2005); however there is a lack of remote-sensing-based research on the condition of Mauritanian ecosystems and its link to climatic conditions. Therefore, the aim of this work was to study the trends and dynamics of the arid and semi-arid ecosystems in Mauritania during 1983-2003, and the response of these to rainfall in the different ecological zones using NOAA-NDVI and rainfall time series. We selected data from 1983 - the driest year of the study period for Mauritania (Anyamba \& Tucker 2005) - to evaluate the level of recovery after the severe drought and avoid the missing values in the start point.

\section{METHODS}

\subsection{Study area}

Mauritania is located in northwest Africa, bordering Senegal and Mali in the South, Mali in the east, Algeria and Morocco in the North and the Atlantic Ocean to the west. The climate is arid in the north and semi-arid in the south. There are 5 ecological zones: west Sahel, east Sahel, Sahara, Senegal River valley and coastal zones (Fig. 1). The mean annual rainfall increases gradually from $<50 \mathrm{~mm}$ in northern Mauritania to around $400 \mathrm{~mm}$ in southern Mauritania. The predominant activities are livestock breeding, agriculture and exploitation of forest resources for shelter, logs and fuel wood (Thiam 2003). The grassland represents the main vegetation cover in the country with shrubs and herbaceous plants. Deforestation by man has led to the disappearance of the majority of the forests in Maurita- nia. Rain-fed agriculture is the most practiced activity in rural areas, while irrigated agriculture is limited to some areas in the Senegal River valley. Historically, livestock breeding is the main economic activity in west Sahel. In Mauritania, livestock makes up $80 \%$ of total agricultural production and represents $22 \%$ of the gross national product (Thys \& Wilson 1996). Livestock breeding and other agricultural activities are mainly practiced in the southern part of the country (SaharoSahelian and Sahelian). However, in the north (the Sahara) pastoral activities are limited to camel and sheep breeding, and the only farming activities are found in areas around oases.

\subsection{Data and analysis}

\subsubsection{Data}

Monthly rainfall records at 16 stations (Fig. 1) were supplied by ASECNA (Agence pour la Sécurité de la Navigation Aerienne en Afrique et à Madagascar). Rainfall time series of 11 stations for the period

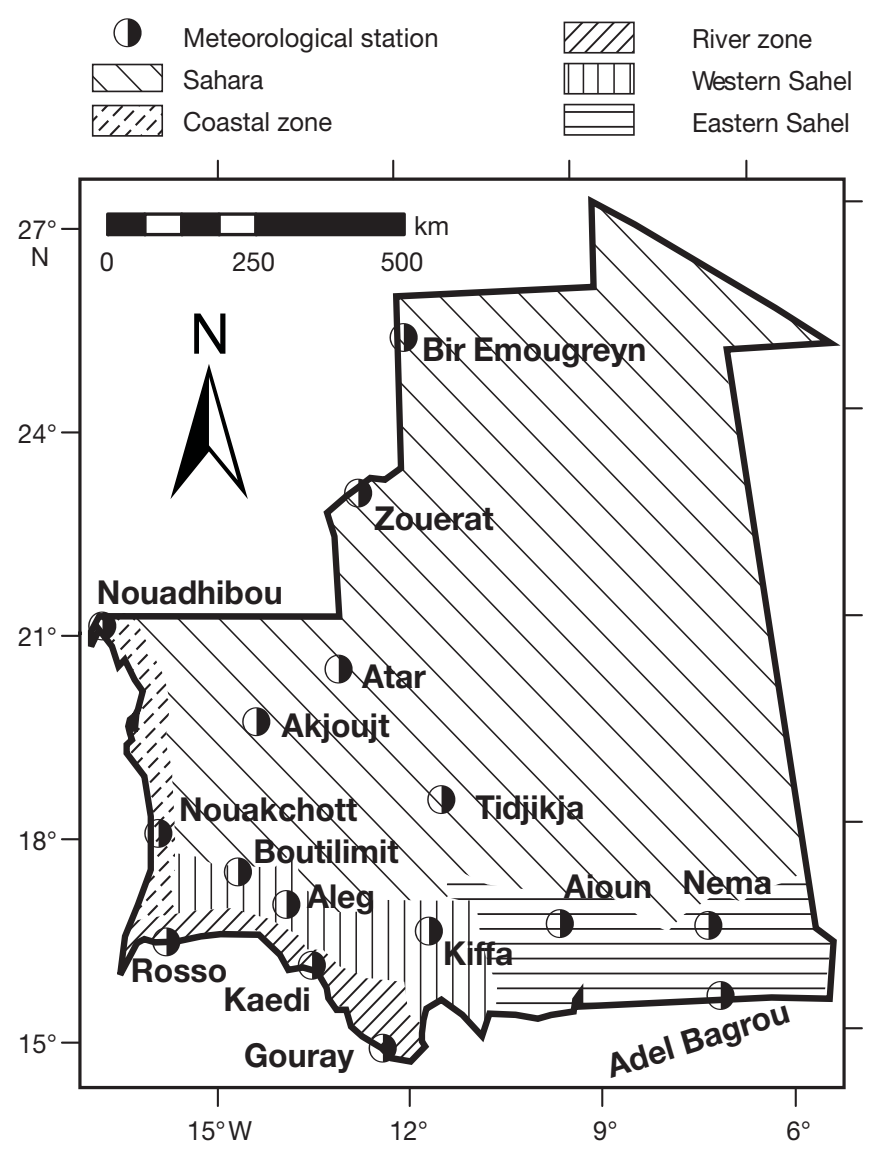

Fig.1. Map of Mauritania with ecological zones and the meteorological station network 
1983-2003 were used to avoid the missing values at the starting point (1982), to analyze the degree of rainfall recovery after the severe drought of 1983 and to evaluate its relationship with NDVI time-series as a proxy for vegetation. Although rainfall time series data was missing for 24 mo (1997-1998) at Adel Bagrou meteorological station and for 12 mo (1988) at Gouray, we felt it would have only minor effects on the power of the statistical tests. The NDVI data set from 1983 to 2003 was selected (from the 1982-2003 period available). The NDVI data set is a bimonthly $8 \mathrm{~km}$ continental product produced by Global Inventory Monitoring and Modeling Studies (GIMMS). These data were obtained from the NASA Distributed Active Archive Center (DAAC), and corrected for cloud affect, solar zenith angle, surface topography and calibrated to handle sensor differences (Tucker et al. 2005, Brown et al. 2006). GIMMS-NDVI data sets show good correlation with data from higher quality sensors, which makes them suitable for use in ecological studies (Pettorelli et al. 2005). For the present study, NDVI annual time series were generated using the maximum value composite (MVC) from the bimonthly GIMMS-NDVI for the rainy season (June to October) in order to reduce the quantity of data. Moreover, time series of mean NDVI-MVC in 10-pixel areas around each meteorological station were produced for the 1983-2003 period to analyze interannual NDVI trends at different stations in different ecological zones.

\subsubsection{Linear regression analysis}

Linear regression analysis was used to analyze rainfall and NDVI time series. The analysis of NDVI was performed at 3 scales; pixel level, regional level and country level. A pixel-level trends map, which provides a clear image of the spatial distribution of changes, was generated by linear regression slope. Trend analysis at the regional level was used to verify the results of pixel-based trends. Two meteorological stations were used in this analysis for the arid zones i.e. Tidjikja and Nouakchott stations for Sahara and coastal zone, respectively, and 3 stations for the other ecological zones i.e. east Sahel (Nema, Adel Bagrou and Aioun), west Sahel (Boutilimit, Aleg and Kiffa) and Senegal River zone (Rosso, Gouray and Kaedi). Finally, we analyzed the trends of the annual mean of rainfall time series and NDVI time series for the whole country.

Student's $t$-test was used to calculate the significance level of regression parameters. The slope was considered as not significantly different from zero at 0.05 level of probability (p). Moreover, we calculated the significance of Lag 1 serial correlation following the method described by Mirza et al. (1998) to increase the variance and to remove the effect of serial correlation.

\subsubsection{Mann-Kendall test}

The linear regression method is widely used for analysis of climatology time-series and NDVI tendency (Fuller 1998, Slayback et al. 2003, Li et al. 2004). However, meteorological data are similar to NDVI time series in that they describe quasi-periodic patterns and fail to meet most of the assumptions necessary for simple linear regression (de Beurs \& Henebry 2004). The most appropriate alternative is the application of a non-parametric test such as Mann-Kendall $(S)$ as it is robust against deviation from normality and missing values. Here, the simple $S$-test was used to assess the trends of annual time series of rainfall and NDVI for different ecological zones and the whole country, while the seasonal $S$ ( $S_{\text {seasonal }}$ )-test was used to analyze the trends of monthly rainfall time series in different stations, monthly average in different ecological zones and monthly average for the whole country.

The presence of serial correlation can complicate the identification of trends (Burn \& Hag Elnur 2002). The pre-whitening method is the most commonly used procedure to remove the effects (Type I and II errors) of serial correlation on $S$ trend analysis and to prevent the false detection of non-existent trends (Von Storch \& Navarra 1995). Therefore, prior to applying the $S$-test, the rainfall and NDVI series were pre-whitened according to a procedure described by Wang \& Swail

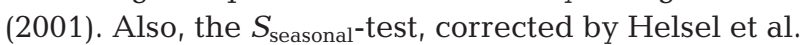
(2006) for serial correlation effects, was employed for monthly rainfall trends analysis.

A positive (negative) value of the $S$-statistic, indicates increasing (decreasing) trends of rainfall and NDVI time series in which the observation augments with time. To test the significance of trends at certain $p$ levels, the null hypothesis is rejected for an absolute $Z$ score at $5 \%$ significance level.

\subsubsection{Coefficient of variation}

NDVI interannual coefficient of variation (CV) has been used to assess vegetation activities and changes in arid and semi-arid regions (Tucker et al. 1991, Weiss \& Milich 1997, Vicente-Serrano et al. 2006). Milich \& Weiss (2000) reported that high CVs embedded among larger areas of much lower CVs may be associated with rapid, dynamic and irreversible (on human timescales) land degradation. Therefore, NDVI-CV was computed according to Weiss \& Milich's (1997) method and compared with results of vegetation dynamics. 


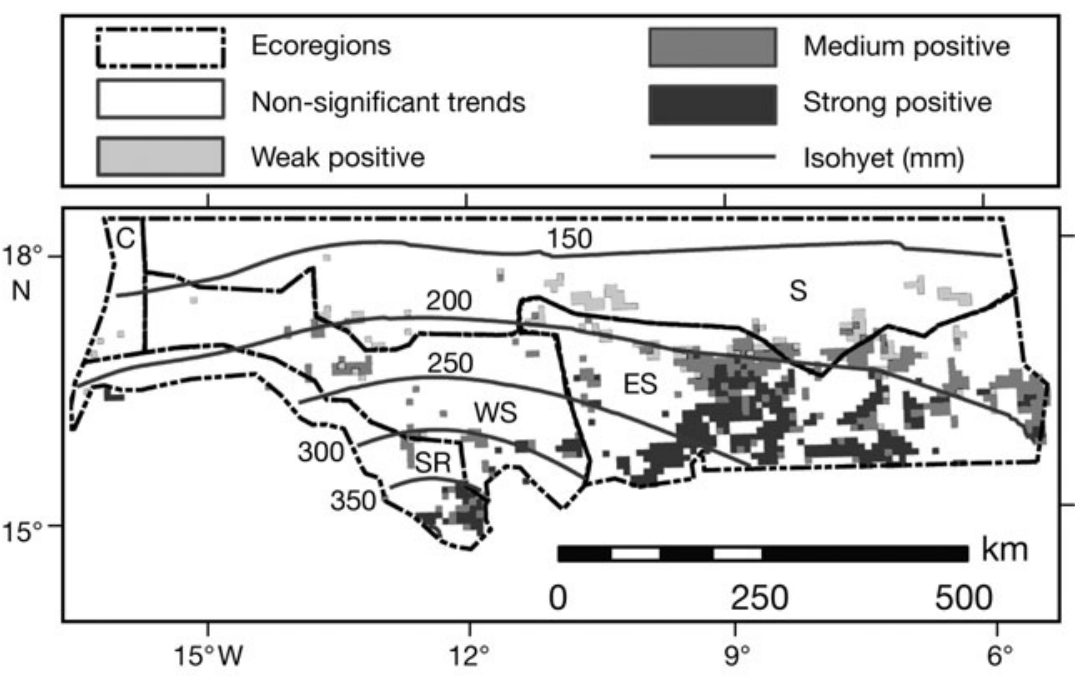

Fig. 2. Map of NDVI linear regression slope (insignificant trends: -0.001 to 0 ; weak positive: 0 to 0.0035 ; medium positive: 0.0035 to 0.0075 ; strong positive: 0.0035 to 0.015$)$, with isohyets of mean annual rainfall (50 $\mathrm{mm}$ interval). Dashed lines: borders of ecological zones; zones-S: Sahara, C: coastal, SR: Senegal River, WS: west Sahel, ES: east Sahel

\section{RESULTS AND DISCUSSION}

Fig. 2 shows the spatial distribution of NDVI trends (using linear regression analysis) during 1983-2003. Significant trends ( $\geq 90 \%$ confidence level) were found in southern Mauritania, mainly the area below $150 \mathrm{~mm}$ isohyet in the east Sahel zone, southeast of the Senegal River zone and in the west Sahel zone. Trends north of the $200 \mathrm{~mm}$ isohyet were insignificant. Anyamba \& Tucker (2005) found significant trends in southern Mauritania around latitude $17^{\circ} \mathrm{N}$.

Vegetation dynamics in the Sahel zone are mainly governed by the pattern of rainfall distribution driven by the African Monsoon system. NDVI and rainfall are highly correlated in the Sahel zone (Herrmann et al. 2005). Therefore, we assumed that any significant rainfall in-
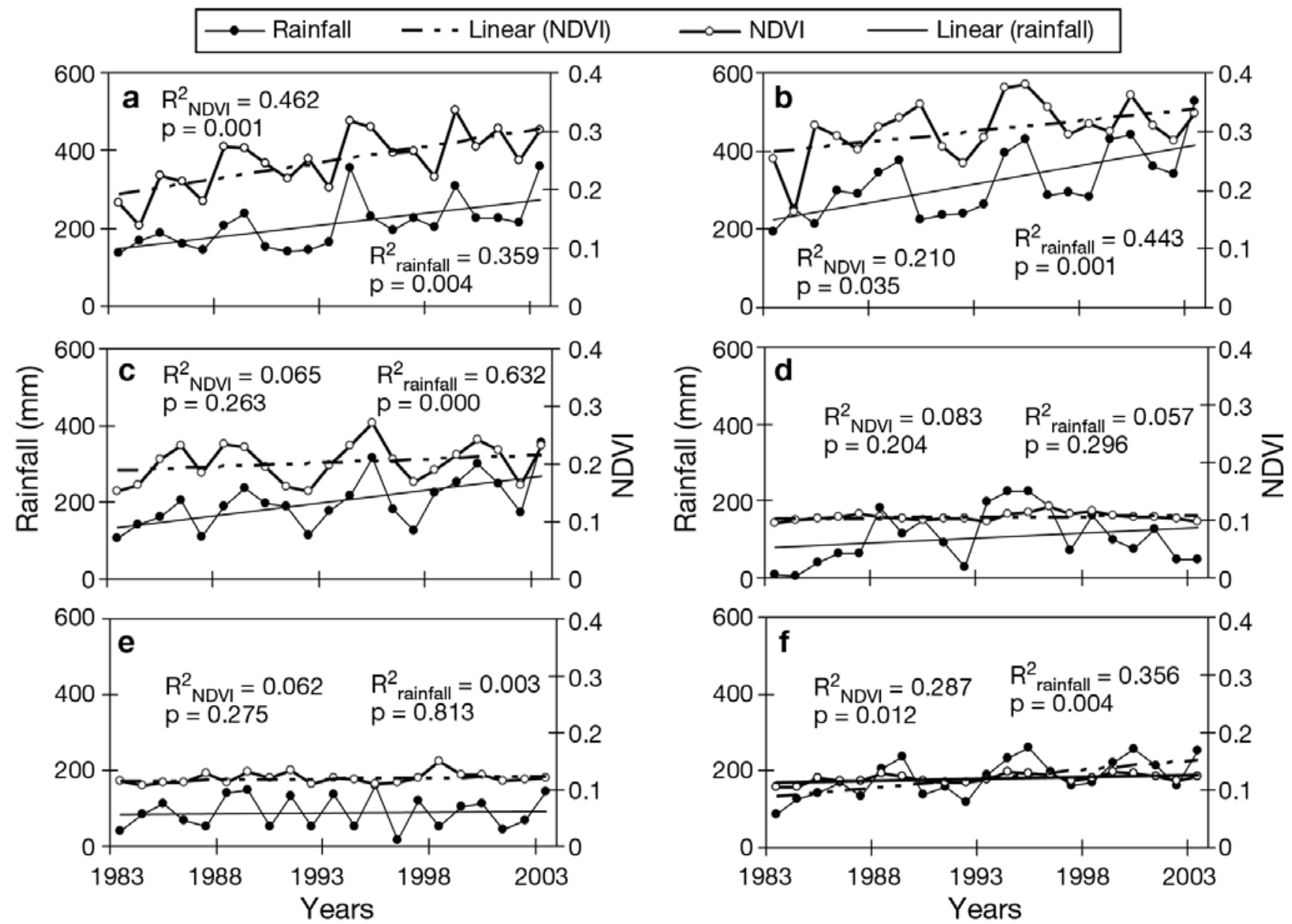

Fig. 3. Time series and linear regression, coefficient of determination of rainfall ( $\mathrm{R}^{2}$ rainfall) and NDVI ( $\left.\mathrm{R}^{2}{ }_{\mathrm{NDVI}}\right)$ for: (a) east Sahel, (b) Senegal River, (c) west Sahel, (d) coastal, (e) Sahara zones, (f) all Mauritania 
crease in the Mauritanian Sahel would be accompanied by significant vegetation (NDVI) increase in productive grass and/or savannah areas. Where there was no greenness after a significant increase in rainfall, land degradation or low land performance were expected (Li et al. 2004).

The descriptive statistics of annual rainfall are presented in Table 1. Rainfall mean values decreased gradually from $482.9 \mathrm{~mm}$ at Gouray (Senegal River zone) to $<170 \mathrm{~mm}$ at Boutilimit (west Sahel zone) and Tidjikja (southern border of Sahara zone). CVs ranged from 0.25 at Adel Bagrou to 0.53 at Nema (east Sahel zone). A CV of 0.51 at Boutilimit (west Sahel zone) indicated high variability in rainfall. The standard deviation (SD) showed high variability ranging from $170.3 \mathrm{~mm}$ at Gouray (Senegal River zone) to $51.7 \mathrm{~mm}$ at Tidjikja (Sahara zone).

The pattern and linear regression analysis of mean rainfall and NDVI for different ecological zones and all Mauritania is shown in Fig. 3 and the results of the statistical analysis are summarized in Table 2. The results indicate significantly increasing rainfall for Mauritania and for different ecological zones except Saharan and coastal zones. On the other hand, the NDVI increased at the whole country level ( $p=0.088$ ) and increased significantly in the east Sahel zone ( $p=0.001)$.

The non-parametric simple $S$ - and $S_{\text {seasonal-tests for rainfall and NDVI time }}$ series indicated significantly increasing trends $(p \leq 0.01)$ at all stations of the east Sahel zone (Table 3). However, in west Sahel, the rainfall trend was only significantly positive at Kiffa. The NDVI series exhibited non-significant increases at Aleg and Boutilimit and insignificant decrease at Kiffa. For the Senegal River zone, Gouray exhibited significant upward trends in rainfall and NDVI, and at Rosso the rainfall increase was not followed by an increase in NDVI. At Kaedi, Nouakchott and Tidjikja, no significant trends were found for either time series.

Unlike the results for regression analysis, the $S$-test showed non-significant trends in NDVI time series for the whole country; this is logical regarding the broad cover of unproductive desert and the absence of significant vegetation recovery in the Senegal River and west Sahel zones.
Table 1. Maximum, minimum and mean rainfall records (in $\mathrm{mm}$ ) and their coefficients of variation (CV) and standard deviation (SD, mm) for 11 meteorological stations in Mauritania

\begin{tabular}{|lrrrrr|}
\hline Station & Max. & Min. & Mean & CV & SD \\
\hline Adel Bagrou & 313.0 & 109.0 & 221.4 & 0.25 & 54.8 \\
Aioun & 313.8 & 117.2 & 203.2 & 0.31 & 62.2 \\
Nema & 450.6 & 42.9 & 205.2 & 0.53 & 109.1 \\
Aleg & 407.0 & 92.0 & 215.1 & 0.41 & 88.0 \\
Boutilimit & 311.4 & 25.3 & 154.7 & 0.51 & 78.4 \\
Kiffa & 515.3 & 112.6 & 245.2 & 0.38 & 93.2 \\
Kaedi & 399.2 & 177.5 & 261.5 & 0.25 & 65.4 \\
Gouray & 974.0 & 241.0 & 482.9 & 0.35 & 170.3 \\
Rosso & 393.2 & 36.6 & 228.1 & 0.42 & 95.0 \\
Nouakchott & 442.0 & 107.0 & 224.9 & 0.31 & 82.0 \\
Tidjikja & 290.0 & 39.0 & 164.0 & 0.33 & 51.7 \\
\hline
\end{tabular}

Table 2. Regression analysis of rainfall and NDVI time series $(\mathrm{N}=21)$ showing the slope value, Lag 1 serial correlation $\left(\mathrm{r}_{1}\right)$, standard error (SE), $t$-test $(t)$ and $t$ probability $(p)$ for different regions and for the whole country. ${ }^{*}$ Significant $(p<0.05)$

\begin{tabular}{|llccccc|}
\hline Region & Series & Slope & $\mathrm{r}_{1}$ & $\mathrm{SE}$ & $t$ & $\mathrm{p}$ \\
\hline East Sahel & Rainfall & 6.23 & 0.19 & 1.908 & 3.26 & 0.004 \\
& NDVI & 0.006 & 0.30 & 0.0010 & 4.04 & 0.001 \\
West Sahel & Rainfall & 6.54 & 0.17 & 1.993 & 3.28 & 0.004 \\
& NDVI & 0.001 & 0.18 & 0.0010 & 1.24 & 0.228 \\
Senegal River & Rainfall & 9.45 & $0.36^{*}$ & 3.462 & 2.73 & 0.013 \\
& NDVI & 0.004 & $0.32^{*}$ & 0.0020 & 1.64 & 0.116 \\
Coastal & Rainfall & 2.71 & $0.45^{*}$ & 3.970 & 0.68 & 0.502 \\
\multirow{3}{*}{ Sahara } & NDVI & 0.000 & $0.49^{*}$ & 0.0004 & 0.78 & 0.442 \\
\multirow{3}{*}{ Mauritania } & Rainfall & 0.41 & $-0.53^{*}$ & 0.915 & 0.45 & 0.659 \\
& NDVI & 0.000 & 0.11 & 0.0004 & 1.12 & 0.275 \\
& Rainfall & 4.76 & $0.33^{*}$ & 2.034 & 2.34 & 0.030 \\
& NDVI & 0.001 & $0.43^{*}$ & 0.0003 & 1.79 & 0.088 \\
\hline
\end{tabular}

Table 3. Simple Mann-Kendall $(S)$-test of NDVI and seasonal $S$-test $\left(S_{\text {seasonal }}\right)$ of rainfall time series $(\mathrm{N}=21)$ showing test Tau coefficient (Tau Coef.), $S$-test statistic, $Z$-score and test probability (p)

\begin{tabular}{|c|c|c|c|c|c|c|c|c|}
\hline \multirow{2}{*}{ Region } & \multicolumn{4}{|c|}{$-S$-NDVI } & \multicolumn{4}{|c|}{$S_{\text {seasonal }}$-Rainfall } \\
\hline & Tau coef. & $S$ & $Z$ & $\mathrm{p}$ & Tau coef. & $S$ & $Z$ & $\mathrm{p}$ \\
\hline \multicolumn{9}{|l|}{ East Sahel } \\
\hline Adel Bagrou & 0.410 & 86 & 2.56 & 0.010 & 0.065 & 119 & 1.96 & 0.049 \\
\hline Aioun & 0.371 & 78 & 2.32 & 0.020 & 0.067 & 167 & 1.78 & 0.012 \\
\hline Nema & 0.429 & 90 & 2.68 & 0.007 & 0.094 & 237 & 2.77 & 0.005 \\
\hline Mean & 0.438 & 82 & 2.74 & 0.006 & 0.104 & 214 & 2.54 & 0.029 \\
\hline \multicolumn{9}{|l|}{ West Sahel } \\
\hline Kiffa & -0.010 & -2 & -0.03 & 0.976 & 0.092 & 232 & 2.54 & 0.011 \\
\hline Aleg & 0.136 & 31 & 0.97 & 0.330 & 0.033 & 84 & 1.01 & 0.219 \\
\hline Boutilimit & 0.057 & 12 & 0.33 & 0.738 & 0.056 & 142 & 1.55 & 0.119 \\
\hline Mean & 0.181 & 38 & 1.12 & 0.264 & 0.092 & 232 & 2.26 & 0.012 \\
\hline \multicolumn{9}{|l|}{ Senegal River } \\
\hline Rosso & 0.038 & 8 & 0.21 & 0.832 & 0.033 & 84 & 0.89 & 0.037 \\
\hline Gouray & 0.343 & 72 & 2.14 & 0.032 & 0.106 & 217 & 3.17 & 0.001 \\
\hline Kaedi & 0.052 & 26 & 0.81 & 0.417 & 0.053 & 133 & 1.48 & 0.138 \\
\hline Mean & 0.095 & 18 & 0.55 & 0.581 & 0.079 & 179 & 1.91 & 0.028 \\
\hline \multicolumn{9}{|l|}{ Coastel } \\
\hline Nouakchott & -0.130 & -25 & -0.78 & 0.434 & 0.03 & 76 & 0.88 & 0.479 \\
\hline \multicolumn{9}{|l|}{ Sahara } \\
\hline Tidjikja & 0.189 & 36 & 1.14 & 0.256 & 0.034 & 86 & 0.92 & 0.404 \\
\hline Mauritania & 0.168 & 32 & 1.00 & 0.314 & 0.096 & 239 & 2.12 & 0.027 \\
\hline
\end{tabular}


The results of both methods, parametric and nonparametric, confirmed the upward trends of rainfall time series in different ecological zones except for the Sahara and coastal zones. At the same time, NDVI time series trends were increasing in the east Sahel zone and part of the Senegal River zone (i.e. Gouray). The correlation coefficients of rainfall and NDVI time series indicated highly significant correlations for the whole country $(r=0.87, \mathrm{p}<0.001)$, east Sahel $(\mathrm{r}=0.77, \mathrm{p}<$ $0.001)$ and west Sahel $(r=0.68, p<0.001)$. However, the correlation was less $(r=0.54, p<0.001)$ in the river zone, which could be attributed to the nature of land use in certain areas along the Senegal River. For the coastal zone at Nouakchott, the correlation $(r=0.50)$ was significant $(p=0.01)$ in spite of apparent persistency of drought at this area. On the other hand, at Tidjikja (Sahara zone) there was very low correlation ( $\mathrm{r}=$ 0.08 ) between NDVI and rainfall time series.

The inter-annual NDVI-CV indicated high variability in the Mauritanian Sahel (Fig. 4). The east Sahel zone had a CV value higher than 0.3 in the area between 200 and $250 \mathrm{~mm}$ isohyets. The Senegal River and west Sahel zones also showed high NDVI variabil-
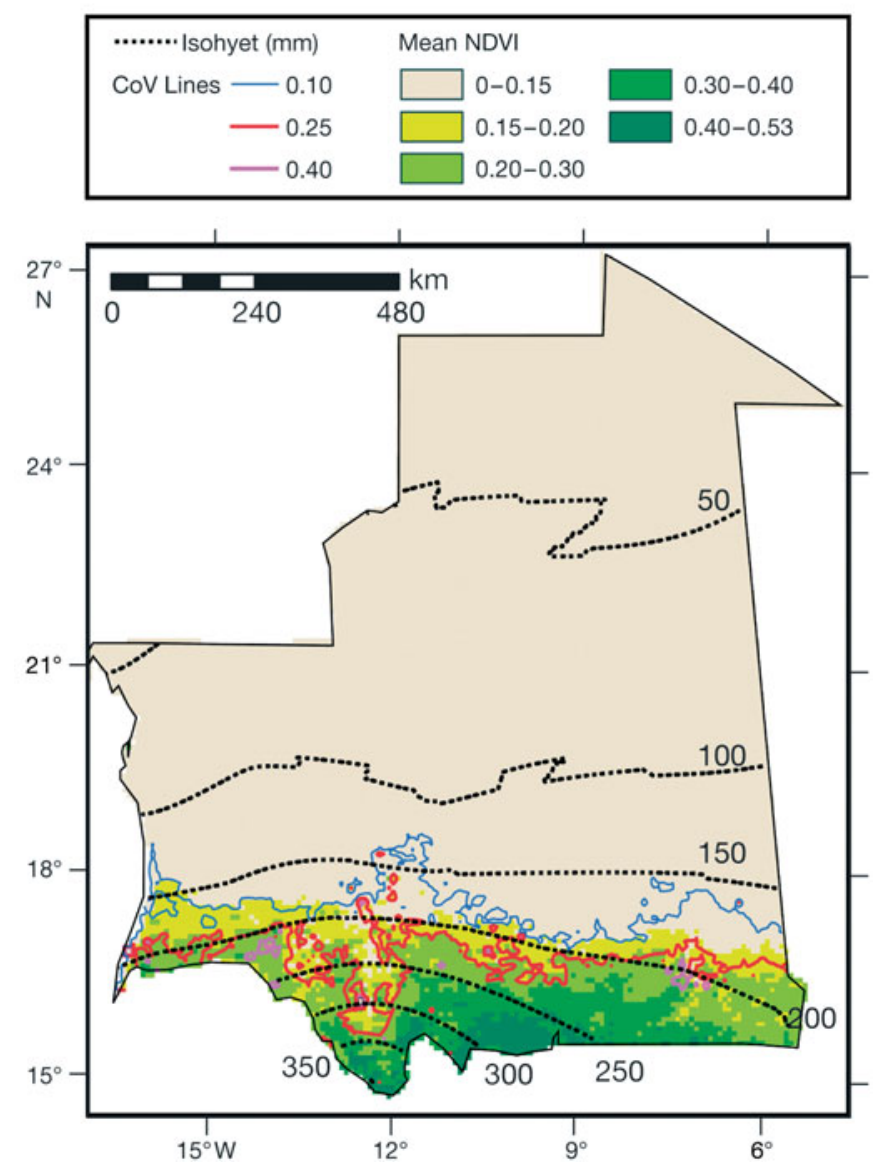

Fig. 4. Coefficient of variation (CV) lines overlaid on the mean NDVI-MVC and rainfall isohyets (50 $\mathrm{mm}$ interval) for 1983-2003 ity. The threshold value 0.25 of interannual NDVI-CV was approximately close to the $200 \mathrm{~mm}$ isohyet, which is regarded to be the northern boundary of the Sahelian region. This area also had an average NDVI-MVC $>0.20$. Therefore, this confirmed the usefulness of 0.25 $\mathrm{CV}$ for defining the Sahelian borders. The patchy areas of high CV were located outside the areas of significant increasing trends (green in Fig. 4), which confirmed the assumption of Milich \& Weiss (2000) that high CVs located between large areas of low CV are an indication of degradation and not of improvement.

Livestock grazing and human practices are generally considered to have similar effects to the climatic conditions that are affecting the Sahel environments. However, among climatic factors, rainfall has been considered as the major driving force of vegetation patterns in the Sahel zone.

The results of this study showed marked greenness in the east Sahel zone, and patchy areas of green in the west Sahel zone and the southeastern part of the Senegal River zone (Fig. 2). This area is known to be the main pastoral zone in the country that experienced, in recent decades, a considerable increase in livestock numbers. For instance, the number of sheep in 1973 was approximately $3 \times 10^{6}$ (Le Houerou 1980) and increased to around $8.85 \times 10^{6}$ in 2006 (FAO 2006). Therefore, this increase in livestock could be attributed to the recent increases in rainfall and greenness in the region. Furthermore, this provides evidence that this semi-arid zone has a higher carrying capacity than was previously assumed. On the other hand, in the western part of the country, the absence of strong vegetation recovery - in spite of significant increases in rainfall amounts and the presence of the highest CVs-confirms that land here is being degraded. Thus, land performance in the east Sahel and southern Senegal River zones was high while in the western part performance was low. Moreover, as this part (the west Sahel and west Senegal River zones) is a principally agro-pastoral zone, human activities can be attributed to the changes more than the climatic conditions.

\section{CONCLUSIONS}

Rainfall and NDVI time series during 1983-2003 showed significant positive trends in southern Mauritania, in the east Sahel zone and in the southeastern part of the Senegal River zone. However, the western part of Senegal River zone and the west Sahel zone showed no significant change in vegetation, in spite of the significant increase in rainfall.

The presence of high interannual NDVI-CV values in areas of significant greenness confirmed the pres- 
ence of degradation in the western Sahel and western Senegal River zones. Moreover, the $0.25 \mathrm{CV}, 0.20$ mean NDVI and $200 \mathrm{~mm}$ isoheyt were almost overlapping. Therefore, these values could be used for the demarcation of the north Sahelian limits. We also suggest the use of the $0.10 \mathrm{CV}$ and 0.15 mean NDVI-MVC to demarcate the northern limits of Sahara-Sahel transition zone.

Regarding the results of the current study and the nature of human activities in different ecological zones - at least in the semi-arid Mauritanian Sahel-it is unlikely that overgrazing is the main cause of ecosystem degradation, but agricultural practices and fuel wood collection may play an important role.

Acknowledgements. This research was supported by MONBUSHO (Ministry of Education, Science, and Culture, Japan). We thank Dr. I. S. A. Tahir (Arid Land Research Center), Prof. J. Wang (Cold and Arid Regions Environmental and Engineering Research Institute) and Dr. A. Hirano (Japan International Research Center for Agricultural Sciences) for their valuable assistance. DAAC and ASECNA (Nouakchott) provided the data sets.

\section{LITERATURE CITED}

Ahmedou OCA, Yasuda H, Wang K, Hattori K (2008) Characteristics of precipitation in northern Mauritania and its links with sea surface temperature. J Arid Environ, doi:10.1016/j.jaridenv.2008.07.011

Anyamba A, Tucker CJ (2005) Analysis of Sahelian vegetation dynamics using NOAA-AVHRR NDVI data from 1981-2003. J Arid Environ 63:596-614

Brown ME, Pinzón JE, Didan K, Morisette JT, Tucker CJ (2006) Evaluation of the consistency of long-term NDVI time series derived from AVHRR, SPOT-vegetation, seaWiFS, MODIS, and Landsat ETM+ sensors. IEEE Trans Geosci Rem Sens 44:1787-1793

Burn DH, Hag Elnur MA (2002) Detection of hydrologic trends and variability. J Hydrol (Amst) 255:107-122

De Beurs KM, Henebry GM (2004) Trend analysis of the Pathfinder AVHRR Land (PAL) NDVI data for the deserts of central Asia. IEEE Geosci Remote Sens Lett 1:282-286

> Demarrée GR (1990) An indication of climatic change as seen from the rainfall data of a Mauritanian station. Theor Appl Climatol 42:139-147

Diouf A, Lambin EF (2001) Monitoring land-cover changes in semi-arid regions: remote sensing data and field observations in the Ferlo, Senegal. J Arid Environ 48:129-148

FAO (2006) The FAO crop and grassland service (AGPC), FAO, Rome, www.fao.org/ag/AGP/AGPC/doc/Counprof/ mauritania/mauritania.htm (accessed 2nd February 2008)

$>$ Fuller DO (1998) Trends in NDVI time series and their relation to rangeland and crop production in Senegal, 19871993. Int J Remote Sens 19:2013-2018

Helsel DR, Mueller DK, Slack JR (2006) Computer program for the Kendall family of trend tests: US Geological Survey Scientific Investigations. Report 2005-5275, USGS, Richmond, VA

> Herrmann SM, Anyamba A, Tucker CJ (2005) Recent trends

Editorial responsibility: Mikhail A. Semenov,

Harpenden, UK in vegetation dynamics in the African Sahel and their relationship to climate. Glob Environ Change 15:394-404

Hickler T, Eklundh L, Seaquist JW, Smith B, Ardö J, Olsson L, Sykes MT, Sjöström M (2005) Precipitation controls Sahel greening trend. Geophys Res Lett 32:L21415, doi:101029/ 2005GL024370

Le Houerou HN (1980) The rangelands of the Sahel. J Range Manage 33:41-46

Li J, Lewis J, Rowland J, Tappan G, Tieszen LL (2004) Evaluation of land performance in Senegal using multi-temporal NDVI and rainfall series. J Arid Environ 59:463-480

Milich L, Weiss E (2000) GAC-NDVI interannual coefficient of variation $(\mathrm{CoV})$ images: ground truth sampling of the Sahel along north-south transects. Int J Remote Sens 21: 235-260

Mirza MQ, Warrick RA, Ericksen NJ, Kenny GJ (1998) Trends and persistence in precipitation in the Ganges, Brahmaputra, and Megna river basins. Hydrol Sci J 43:845-858

Nicholson SE (2000) Land surface process and Sahel climate. Rev Geophys 38:117-139

Nicholson SE (2005) On the question of the 'recovery' of the rains in the West African Sahel. J Arid Environ 63:615-641

> Olsson L, Eklundh L, Ardö J (2005) A recent greening of the Sahel-trends, patterns and potential causes. J Arid Environ 63:556-566

Pettorelli N, Vik JO, Mysterud A, Gaillard JM, Tucker CJ, Stenseth NC (2005) Using the satellite-derived NDVI to assess ecological responses to environmental change. Trends Ecol Evol 20:503-510

Slayback DA, Pinzon J, Los SO, Tucker CJ (2003) Northern hemisphere photosynthetic trends 1982-99. Glob Change Biol 9:1-15

Tappan G, Sall M, Wood E, Cushing M (2004) Ecoregions and land-cover trends in Senegal. J Arid Environ 59: $427-462$

Thiam AK (2003) The causes and spatial pattern of land degradation risk in southern Mauritania using multitemporal AVHRR-NDVI imagery and field data. Land Degrad Dev 14:133-142

Thys E, Wilson RT (1996) Age and sex composition of small ruminants at Nouakchott markets, Mauritania. Small Rumin Res 20:281-284

Tucker CJ, Newcomb WW, Los SO, Prince SD (1991) Mean and inter-year variation of growing-season normalized difference vegetation index for the Sahel 1981-1989. Int J Remote Sens 12:1133-1135

Tucker CJ, Pinzon JE, Brown ME, Slayback DA and others (2005) An extended AVHRR 8-km NDVI dataset compatible with MODIS and SPOT vegetation NDVI data. Int J Remote Sens 26:4485-4498

Vicente-Serrano SM, Cuadrat-Prats JM, Romo A (2006) Aridity influence on vegetation patterns in the middle Ebro Valley (Spain): evaluation by means of AVHRR images and climate interpolation techniques. J Arid Environ 66: 353-375

Von Storch H, Navarra A (1995) Analysis of climate variability. Application of statistical techniques. Springer-Verlag, New York

> Wang LX, Swail VR (2001) Changes of extreme wave heights in Northern Hemisphere Oceans and related atmospheric regimes. J Clim 14:2204-2221

> Weiss E, Milich L (1997) errors in a standard method for generating interannual NDVI coefficient of variation (CV) images. Int J Remote Sens 18:3743-3748

Submitted: February 4, 2008; Accepted: September 8, 2008

Proofs received from author(s): November 15, 2008 